University of Louisville

ThinkIR: The University of Louisville's Institutional Repository

Electronic Theses and Dissertations

$5-2017$

\title{
Spontaneous vocal matching in mothers and their hearing impaired infants with cochlear implants : a quantitative analysis.
}

Lydia Doggett

University of Louisville

Follow this and additional works at: https://ir.library.louisville.edu/etd

Part of the Speech Pathology and Audiology Commons

\section{Recommended Citation}

Doggett, Lydia, "Spontaneous vocal matching in mothers and their hearing impaired infants with cochlear implants : a quantitative analysis." (2017). Electronic Theses and Dissertations. Paper 2690.

https://doi.org/10.18297/etd/2690

This Master's Thesis is brought to you for free and open access by ThinkIR: The University of Louisville's Institutional Repository. It has been accepted for inclusion in Electronic Theses and Dissertations by an authorized administrator of ThinkIR: The University of Louisville's Institutional Repository. This title appears here courtesy of the author, who has retained all other copyrights. For more information, please contact thinkir@louisville.edu. 
SPONTANEOUS VOCAL MATCHING IN MOTHERS AND THEIR HEARINGIMPAIRED INFANTS WITH COCHLEAR IMPLANTS: A QUANTITATIVE ANALYSIS

\author{
By \\ Lydia Doggett \\ B.S.- University of Kentucky, Lexington, May 2015 \\ A Thesis \\ Submitted to the Faculty of the \\ School of Medicine of the University of Louisville \\ in Partial Fulfillment of the Requirements \\ for the Degree of \\ Masters of Science \\ in Communicative Disorders \\ Department of Otolaryngology Head and Neck Surgery and Communicative \\ Disorders \\ University of Louisville \\ Louisville, Kentucky
}

May 2017 
(C) 2017 by Lydia Doggett

All rights reserved 

SPONTANEOUS VOCAL MATCHING IN MOTHERS AND THEIR HEARINGIMPAIRED INFANTS WITH COCHLEAR IMPLANTS: A QUANTITATIVE ANALYSIS

\author{
By \\ Lydia Doggett \\ B.A.- University of Kentucky, Lexington, May 2015 \\ A Thesis Approved on \\ April 21, 2017 \\ by the following Thesis Committee:
}

Teresa Pitts, Ph.D., Thesis Director

Maria Kondaurova, Ph.D.

Alan Smith, Ph.D.

Melanie Soderstrom, Ph.D. 


\section{DEDICATION}

To my mentor, Dr. Kondaurova, who has supported and assisted an extremely unexperienced student through the monstrous process of completing a first research project. To my parents and my family, who taught me the value of hard work and perseverance. To my teachers and professors throughout the years, especially my graduate professors, who have willingly and passionately passed on their academic knowledge, but also have taught by example what it takes to be caring, passionate, and dedicated, both in academia and in life. To my friends and classmates, who have been so supportive during this process-we made it! And finally, to my "buddy", for being my best friend and being with me every step of the way-I love you. 


\section{ACKNOWLEDGMENTS}

This research was supported by National Institute on Deafness and Other

Communication Disorders Grant R01 DC008581 to Dr. D.M. Houston at the Ohio State

University. We especially thank the families that participated in this study. 


\begin{abstract}
SPONTANEOUS VOCAL MATCHING IN MOTHERS AND THEIR HEARINGIMPAIRED INFANTS WITH COCHLEAR IMPLANTS: A QUANTITATIVE ANALYSIS

Lydia M. Doggett
\end{abstract}

April 21, 2017

Vocal matching, the ability to imitate phonetic properties of speech, was examined in spontaneous interactions of sixteen dyads of mothers and their hearingimpaired (HI) infants with cochlear implants and age-matched normal-hearing (NH) infants. Mother-infant dyads came to three sessions at three, six, and 12 months postimplantation. Vocal matching was defined as an instance of perceptual and acoustic similarity of vowels and consonants between adjacent maternal and infant utterances. Vocal matching occurred in $25 \%$ to $50 \%$ of infant and in $17 \%$ to $64 \%$ of mother vocalizations across dyads. Both mothers and infants in the HI group produced fewer matches as compared to the $\mathrm{NH}$ group. However, the number of matches increased in both groups over the period of three testing sessions. These results suggest that vocal matching is a part of interactions between mothers and their $\mathrm{HI}$ infants and that pediatric hearing loss affects both infants' and mothers' imitative abilities. 
TABLE OF CONTENTS

PAGE

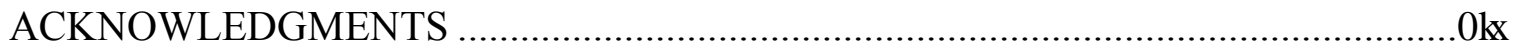

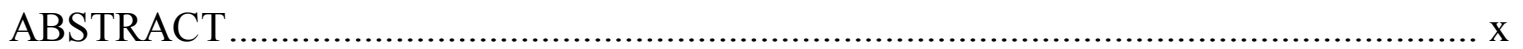

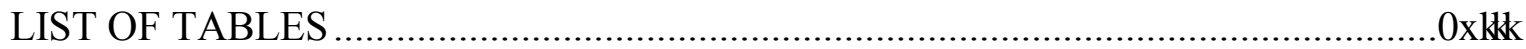

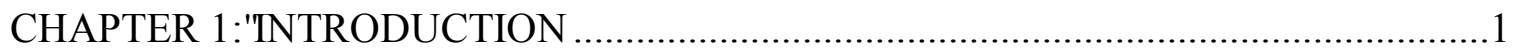

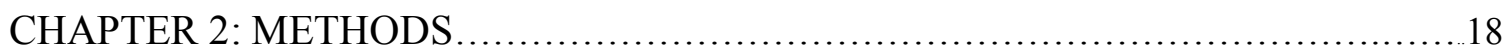

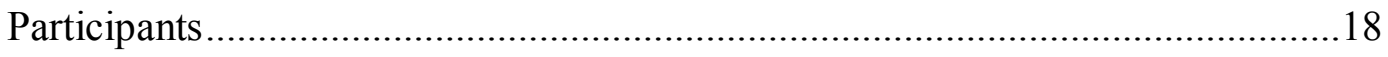

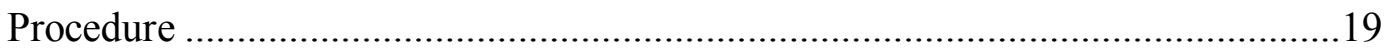

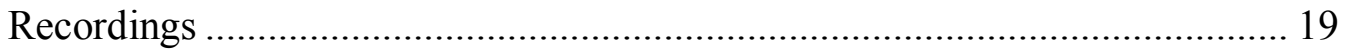

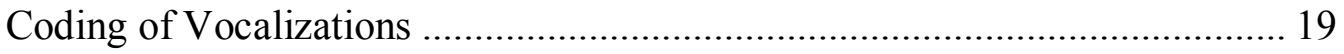

Matching Score Calculation............................................................................. 20

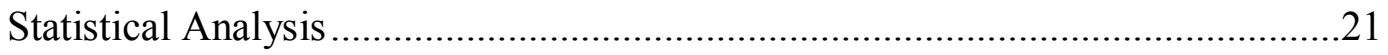

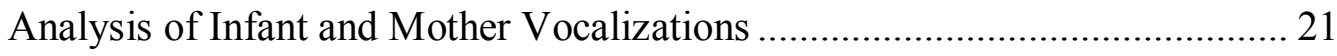

Analysis of Infant and Mother Vocalizations with a Matching Score $>0$....... 22

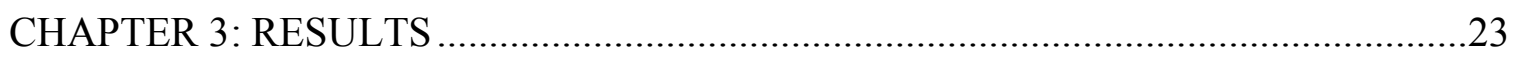

Infant and Mother Vocalizations ......................................................................23

The Number of Infant and Mother Utterances....................................................23

The Number of MI and IM Turns ..................................................................24

The Length of Utterances in Number of Sounds .................................................24

Infant and Mother Vocalizations with a Matching Score $>0$.................................25

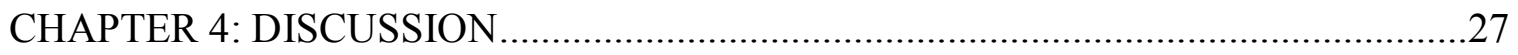




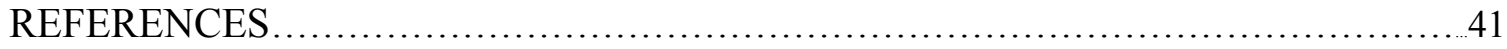

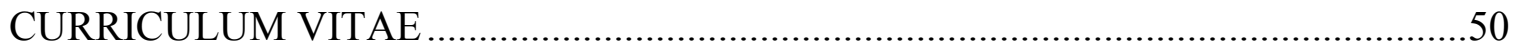




\section{LIST OF TABLES}

TABLE

PAGE

Table 1. Number of dyads, mean age of infants at each session, and sex of infants,

presented as mean $\pm \mathrm{SE}$ 34

Table 2. Communication method, deafness etiology, and the type of CI device 35

Table 3. Mean number of utterances, mother-infant and infant-mother turns and mean

length of utterances in phonemes in $\mathrm{HI}$ and $\mathrm{NH}$ groups, presented as mean $\pm \mathrm{SE}$ 36

Table 4. Length of utterances in phonemes and as a proportion of a preceding utterance in mother-infant and infant-mother turns, presented as mean \pm SE ................................. 37

Table 5. Proportion of infant and mother utterances with a matching score $>0$ out of all mother-infant and infant-mother turns in $\mathrm{HI}$ and $\mathrm{NH}$ groups, presented as mean $\pm \mathrm{SE} \ldots 38$ 


\section{CHAPTER 1}

\section{INTRODUCTION}

Communication between a mother and her infant is a dynamic interaction that requires both the mother and the infant to take active roles as communication partners (Papousek \& Papousek, 1989; Snow, 1977). One adjusts their behavior to link it with a partner's previous behavior; this is known as "contingent behavior" (Beebe et al., 2010). The presence of contingency in mother-infant interactions has been associated with positive outcomes in many areas of infant development, including language (Goldstein, King, \& West, 2003; Goldstein \& Schwade, 2008; Hudson, Levickis, Down, Nicholls, \& Wake, 2015). For example, infants who received contingent feedback from mothers were found to produce more complex and advanced forms of vocalizations compared to infants who did not receive contingent feedback (Goldstein et al., 2003; Goldstein \& Schwade, 2008). Another study showed that maternal contingency in interactions with their slowto-talk infants was correlated with higher expressive, receptive, and total language scores at three and four years of age (Hudson et al., 2015).

Vocal imitation, also known as vocal matching, is an important characteristic of contingent behavior, as well as a strategy in child language acquisition process (Papousek, 1992; Pelaez, Virues-Ortega, \& Gerwirtz, 2011). Vocal imitation is defined as "an attempt, intentional or incidental, to match an auditory event with the vocal motor system" (Mercado, Mantell, \& Pfordresher, 2014). The purpose of this study is to 
investigate how mothers and infants, both with normal hearing $(\mathrm{NH})$ and with hearing loss (HL), imitate each other on a segmental level during spontaneous speech.

Past research has shown that infants begin to use vocal imitation as early as $12-20$ weeks of age (Kuhl \& Meltzoff, 1996). These early imitations are limited to open mouth vowels with little modulation (Heimann, 1998; Kugiumutzakis, 1998, 1999). With age, infants begin to imitate consonant sounds and vowel-consonant combinations (Gazdag \& Warren, 2000). Children typically progress from partial or reduced imitations, to exact imitations, to expanded imitations (Gazdag \& Warren, 2000; Kucjaz, 1983; Snow, 1981). Imitation of novel words typically emerges during the beginning of the second year of life, at the same time that vocabulary acquisition is accelerating (Masur, 1993, 1995).

Previous studies investigated the quantity of infant vocal imitations (Bloom, Hood, \& Lightbown, 1974; Kokkinaki \& Kugiumutzakis, 2000; Kugiumutzakis, 1993; Kuhl \& Meltzoff, 1982; Papousek \& Papousek, 1989). Quantity refers to the number of imitations made by the infants. One study, by Kugiumutzakis (1993), looked at the number of infant imitations of maternal utterances in infants up to six months old. Mothers and their infants were recorded for ten minutes during twelve visits to the home, which took place every two weeks starting when the infant was 15 days old and continuing until the infant was six months old. (Kugiumutzakis, 1993). Recordings were transcribed orthographically and analyzed segmentally, with an imitative event defined as either partner repeating a sound from the previous partner's utterance within two seconds. The study found that infant imitations of mothers' utterances made up 27\% (213) of the total imitations observed (800) (Kugiumutzakis, 1993). These findings are in line with the results of another study conducted by Kokkinaki and Kugiumutzakis (2000). For this 
study, parents were asked to play with their infants as they normally would in the home during a ten-minute video recording session. In this study, imitation was defined as one partner repeating a sound from the previous partner's utterance within a ten second interval. Recordings were segmentally analyzed. This study found that infants imitated at a rate of 3.7 imitations in 10 minutes (Kokkinaki \& Kugiumutzakis, 2000).

Papousek and Papousek (1989) also conducted a study concerning quantity of infant vocal imitations that yielded different results. 17 mothers and their two, three, and five-month-old infants were recorded during spontaneous play interactions for three to five minutes. Vocalizations were analyzed both on the prosodic (absolute pitch, pitch contour, duration, and rhythm) and segmental (vowel-like resonance and consonant-like closure) levels. Prosodic analysis was conducted using auditory and acoustic analysis; Segmental analysis was completed using phonetic transcription. This study found that the number of infant imitations of maternal utterances was similar to that of mother imitations of infant utterances for each age group. At two months, 8.9 Infant-Mother (IM) matches and 7.3 Mother-Infant (MI) matches were recorded; at three months, 12.3 IM matches and 14.2 MI matches were recorded, and at five months 11.0 IM matches and 9.8 MI matches were observed. Overall, this study suggests that infant imitations may make up a larger proportion of total infant utterances than stated in other studies (Papousek \& Papousek, 1989).

Bloom and colleagues (1974) completed a study investigating the percentage of total infant utterances comprised of vocal imitations. Six infants were recorded during interactions with investigators and the infants' mothers (Bloom et al., 1974). At the first session, infants ranged in age from 16 months, three weeks, to 21 months, one week old. 
Recordings were made in the home environment for six to eight hours over several days every three to six weeks (one child's recordings were done in an audiovisual studio at the University of Columbia) (Bloom et al., 1974). Number of sessions recorded ranged from two sessions to six sessions. Both adult and infant utterances were transcribed and analyzed on a segmental level. The study found that the amount of vocal imitation was highly varied for each child. Vocal imitations made up anywhere between three percent and $57 \%$ of each infant's total utterances (Bloom et al., 1974). The study also noted that in general, each infant's individual percentage of vocal imitation remained relatively consistent during the completion of the study (Bloom et al., 1974).

Previous literature has also examined the quality, or segmental aspects, of infant vocal imitations. Overall, past research suggests that infants imitate vowel-like sounds earlier than consonant sounds, and that certain vowel and consonant sounds emerge before others in infant imitations (Kuhl \& Meltzoff, 1982, 1996; Papousek \& Papousek, 1989). One study, by Kuhl and Meltzoff (1996), investigated infants' vocal imitation of vowel sounds. The study was comprised of 72 infants divided into three age groups: 12 , 16, and 20 weeks old (Kuhl \& Meltzoff, 1996). Three sessions were held with each child on consecutive days. Infants were placed in a room and presented with three different auditory-visual face-voice stimuli-/a/, /i/, and /u/. Infant responses were recorded and analyzed perceptually and instrumentally to determine if vocal imitation was present (Kuhl \& Meltzoff, 1996). The study found that all infants, even the infants in the youngest age group, imitated the vowel stimuli that were presented, indicating that infants have the ability to consistently imitate vowel sounds as early as 12 weeks of age (Kuhl \& Meltzoff, 1996). These results were similar to the results of a previous study 
conducted by Kuhl and Meltzoff, in which infants ages 18-20 months imitated vowel stimuli that were presented with auditory and visual models (Kuhl \& Meltzoff, 1982). Another study, by Papousek and Papousek (1989), documented the quality of infant vocal imitations at ages two months, three months, and five months. According to this study, infants' vocal imitations at two months contained mainly low front to central vowels, /a/, and mid central vowels, /ə/. Consonant sounds used at two months included velar plosives, $/ \mathrm{g} /$ and $/ \mathrm{k} /$, and glottal fricative, $/ \mathrm{h} /$. At three months, infants increased their matches of low front to central vowels and mid central vowels, and they also began matching mid to low front vowels, /e/ and / $/$ / and diphthongs. Infants began to match more consonant sounds at three months; however, vowel sounds still made up a larger percentage of infant matches. Matches of velar plosives and glottal fricatives increased, and infants began matching glottal plosive, /2/, labial plosives, /b/ and /p/, palatal fricative, $/ \mathrm{j} /$, labial fricatives, $/ \mathrm{v} / / \mathrm{f} /$ and $/ \beta /$, uvular $\operatorname{trill} / \mathrm{r} /$, and nasal $/ \mathrm{n} /, / \mathrm{m} /$, and - ng. At five months, infants decreased their matching of mid central, mid to low front, and low front to central vowels, and increased their matching of diphthongs and high to mid back vowels, /o/. Matching of glottal fricatives, nasals, and the labial trill sound /B/ in imitations was increased, while matching of velar plosives, glottal plosives, labial plosives, and labial fricatives was decreased in imitative utterances (Papousek \& Papousek, 1989).

This study, as well as others, also documented that vocal imitation in infants develops and becomes more complex over time (Kuhl \& Meltzoff, 1996; Papousek \& Papousek, 1989). In their study, Papousek and Papousek found that that the percentage of infant imitations increased from $41.1 \%$ at two months to $57 \%$ at three months and $58 \%$ 
at five months, indicating that infants imitate more as they mature (1989). They also found that, as infants aged, their imitations became more intricate and began to include more complex features, such as consonant forms, rhythm, duration, and contour (Papousek \& Papousek, 1989).

Kuhl and Meltzoff (1996) also investigated the effect of infant age on imitative vocalizations following vowel stimuli. The study found that as infants aged, their categories of vowels became "increasingly differentiated" and began to more closely approximate adult vowel models (Kuhl \& Meltzoff, 1996, p. 11), indicating that infants become more accurate in their vocal matching as they mature.

Because vocal matching is a bidirectional process, it is also important to look at mothers' role in vocal matching. Previous research has outlined both quantity and quality of maternal vocal matching. Overall, past research has shown that maternal vocal matches tend to be more frequent than infant vocal matches, and that frequency of maternal imitation is dependent on the type of infant utterance that precedes it (GrosLouis, West, Goldstein, \& King, 2006; Kugiumutzakis, 1993; Masur \& Rodemaker, 1999). One study, by Masur and Rodemaker (1999), examined the quantity of mothers' vocal imitations compared to the quantity of infants' vocal utterances. For the study, 20 mother-infant pairs were recruited to record two separate play sessions in their homes at the ages of 10, 13, and 21 months of age (Masur \& Rodemaker, 1999). This study calculated both the verbal imitation, defined as the imitation of convention words and phrases, as well as vocal imitation, defined as "other sounds, including language-related sounds or CV babbles and non-language-related noises" (Masur \& Rodemaker, 1999, p. 7). Results showed that the number of mothers' verbal and vocal imitations, bother 
during free play and bath time, was consistently greater than greater than the number of infant verbal and vocal imitations at all ages, indicating that mothers tend to vocally match their infants more frequently than vice versa (Masur \& Rodemaker, 1999).

Another study, by Gros-Lewis and colleagues, investigate the effect of the type of infant vocalization on the quantity of maternal vocal matching (Gros-Lewis et al., 2006). Ten infant and mother pairs participated in two unstructured play session that lasted for thirty minutes (Gros-Lewis et al., 2006). Recording session took place on consecutive days in a large play room (Gros-Lewis et al., 2006). Infant utterances were coded as vowel-like vocalizations or consonant-vowel vocalizations, and mothers' vocalizations were categorized as naming, questions, acknowledgments, imitations, attributions, directives, or play vocalizations (Gros-Lewis et al., 2006). The study found that mothers were eight times as likely to imitate and expand on infant consonant-vowel utterances compared to vowel-like utterance (Gros-Lewis et al., 2006). Overall, this study indicates that mothers produce more vocal matches in response to "more developmentally advanced" infant vocalizations, demonstrating that the quantity of maternal imitation is affected by the complexity of infants' utterances (Gros-Lewis et al., 2006, p. 6).

Other studies that have examined the quality of maternal imitations found that mothers tend to use expansive imitation as infants age (Masur \& Rodemaker, 1999; Olson \& Masur, 2012). One study by Olson and Masur examined the types of imitations mothers used in response to their infants' imitation of familiar vs. novel words (Olson \& Masur, 2012). Twenty mother-infant dyads were recorded for 30 minute sessions in their homes during natural interactions with toys and during bath time (Olson \& Masur, 2012). Recordings were taken when infants were one year one month, one year five months, and 
one year nine months old. The study examined exact imitations, or responses that were exact copies of the model, reductions, or responses that omitted words from the model without adding new words, expansions, or responses that contained the entire model as well as additional words, and reduction+expansions, or responses that eft out some words from the model and also added additional words not present in the model (Olson \& Masur, 2012). They found that mother altered their imitations depending on the type of imitation used by the infant (Olson \& Masur, 2012). Mothers tended to produce exact or reduced imitations following noon-familiar infant imitations (those words not in the infant's spontaneous productive vocabulary) (Olson \& Masur, 2012). However, when infants imitated familiar words, mother produced expanded imitations, as well as reduction+expansion imitations (Olson \& Masur, 2012).

Like infant vocal matching, maternal vocal matching also changes over time. A study by Masur and Rodemaker investigated how mothers' verbal and vocal imitation of infants changes as infants aged from 10 months to 21 months of age (Masur \& Rodemaker, 1999). This longitudinal study looked at mothers' and infants' imitative vocalizations at the ages of $10,13,17$, and 21 months (Masur \& Rodemaker, 1999). The study showed that during free play, maternal verbal imitation increased at each age mark, with substantial increases at both 17 and 21 months (Masur \& Rodemaker, 1999). Vocal imitation by mothers also increased between 10 and 17 months, but decreased slightly at 21 months (Masur \& Rodemaker, 1999).

Olson and Masur further investigated how maternal imitation and expansion changed over time (Olson \& Masur, 2012). Results showed that during the first set of recordings, when infants were one year and one month old, mothers produced double the 
amount of exact imitations compared to expansions following familiar and novel imitations by the infants (Olson \& Masur, 2012). At one year and five months old, mothers began using expansive imitation in response to infants' imitations of familiar words; however, mothers continued to use more exact and reduced imitations following infant imitations of non-familiar words (Olson \& Masur, 2012). At one year and nine months, mothers increased their use of expansive and reduction+expansion imitations and decreased use of exact imitations (Olson \& Masur, 2012). Overall, the study showed that mothers increase their use of expansive imitation and reduction+expansion imitation as their infants age.

Contingent communication, including vocal matching, is negatively affected when the infant suffers from a hearing loss. Hearing loss interrupts the natural, shared communicative exchanges found in normal hearing mothers and infants (Cross, Nienhuys, \& Kirkman, 1985; Henggeler \& Cooper, 1983). Auditory feedback is essential for motivating early infant vocalizations (Fagan, 2014); therefore, it is not surprising that infants with profound hearing loss vocalize significantly less than normal hearing peers (Fagan, 2014). Other areas of early language development are also affected by hearing loss. For example, infants with severe-to-profound hearing loss were slower to develop canonical babbling, a skill that sets up the foundation for many words in natural languages, than their normal hearing peers (Iyer \& Oller, 2008). Infants with profound hearing loss are also shown to take fewer vocal turns compared to normal hearing peers (Tait, De Raeve, \& Nikolopoulos, 2007).

Hearing is an important part of infant vocal imitation (Kuhl \& Meltzoff, 1996), making vocal imitation problematic for infants with severe-profound hearing loss. 
Previous studies suggest that imitation abilities are negatively affected in infants with HI (Chin, Bergeson, \& Phan, 2012; Dillon, Cleary, Pisoni, \& Carter, 2004; Ertmer \& Goffman, 2011; Ertmer, Kirk, Sehgal, Riley, \& Osberger, 1997; Nakata, Trehub, \& Kanda, 2012; Peng, Tomblin, \& Turner, 2008; Sehgal, Kirk, Svirsky, Ertmer, \& Osberger, 1998). While there is very little past research that investigates naturalistic vocal imitation in hearing impaired infants, there are several studies that looked at imitative abilities of older children with cochlear implants (CIs) by using both non-word and whole word repetition tasks in laboratory settings. One such study, by Cleary, Dillon, and Pisoni (2002), presented a non-word repetition task to 14 children with CI's ages eight to nine years old in a laboratory setting (Cleary, Dillon, \& Pisoni, 2002). Children were instructed to repeat the sounds they perceived, and repetitions were recorded and analyzed segmentally. This study found that most of the children imitated at least part of the target item. However, none of the children produced a perfect imitation (Cleary et al., 2002). The study also found that children who were implanted at a later age tended to have poorer results on the repetition task (Cleary et al., 2002). Linguistic analysis of the attempted repetitions revealed that the voicing feature was the most accurately imitated, followed by manner and place features. Children were more likely to correctly imitate coronal consonants (/t, d, s/) than labial (/p, b/) or velar (/k, g/) consonants (Cleary et al., 2002). If the correct number of syllables were not produced in children's' attempted repetitions, responses tended to have fewer syllables compared to the target (Cleary et al., 2002). Overall, this study demonstrated that, while children with CI's were able to imitate parts of the target words, hearing loss had a negative effect on the children's imitative accuracy (Cleary et al., 2002). 
A follow up study further investigated child CI users' performances on non-word repetition tasks (Dillon et al., 2004). Using the same procedures listed above, the attempted repetitions of 24 children ages eight to nine years old were recorded (Dillon et al., 2004). In this study, five percent of the children's attempted imitations were perfect repetitions of the target words (Dillon et al., 2004). As in the previous study, researchers found that coronal consonants were imitated with the most accuracy, followed by labial and dorsal consonants. Shorter target words (those with two to three syllables) were more likely to be more accurately imitated than target words with four to five syllables. There was a large amount of variation in the children's individual segmental accuracy scores, with scores ranging from eight percent to $76 \%$ (Dillon et al., 2004). This study also compared children's segmental accuracy scores with scores on tests that measured speech and language outcomes. They found children who scored higher on spoken word recognition, language comprehension in terms of receptive vocabulary/morphology/ syntax, and speech intelligibility were more likely have a higher average segmental accuracy score (Dillon et al., 2004). Overall, these results confirmed the results of the previous study, indicating that imitation is problematic who children with hearing loss.

Another study, by Sehgal and colleagues (1998), investigated speech production differences in imitative tasks in children with CIs and hearing aids, both before and one and a half years following device use (Sehgal et al., 1998). Auditory recordings of CV syllables were presented in a laboratory setting, and children's imitative attempts were recorded and analyzed in terms of percent of manner, place, and voicing features that matched the target syllable. Results found that accurate production of the voicing feature was relatively poor for both groups before device use, with an average of $30 \%$ of 
voicing features in target syllables produced accurately (Sehgal et al., 1998). While both groups improved in accuracy after one year of device use, there was a more significant improvement in the production of voicing in children with CI's (median score of $62 \%$ compared to HA median score of 37\%) (Sehgal et al., 1998). Similar results were found in regards to the place of articulation feature; both groups had similar accuracy levels (around 30\%) before device use, and both groups had improved significantly at the postdevice interval, with CI users' gain (median score of 68\%) being greater than that of the HA users' (median score of 46\%) (Sehgal et al., 1998). Pre-device use, both groups produced bilabial consonants with the most accuracy, followed by alveolar consonants (Sehgal et al., 1998). Post-device use, while improvement was noted for all places of articulation, the only significant increase in accuracy was with alveolar consonants in the CI group (Sehgal et al., 1998). For the manner of articulation feature, CI users' median pre-implant accuracy score was $31 \%$ and HA users' median pre-device use accuracy score was 16\% (Sehgal et al., 1998). Stop consonants were produced with the most accuracy and affricates were produced with the lowest level of accuracy for both groups pre-device use (Sehgal et al., 1998). Both groups showed a significant increase in accuracy for the manner of articulation feature post-device use, with CI users' median score improving to $62 \%$ and HA users' improving to $37.5 \%$ (Sehgal et al., 1998). CI users significantly improved their production of all five consonant manner categories post-implant; HA users also improved their manner production accuracy, but not to the extent of the CI group. The difference in improvement between the two groups regarding manner of articulation did not reach significance (Sehgal et al., 1998). Overall, this studied showed that both CI and HA users improved their imitation of voicing, place, and 
manner of production for consonants after one and a half years of device use, with CI users showing significantly more improvement that HA users in the areas of voicing and place of articulation (Sehgal et al., 1998). This study implies that use of assistive devices leads to improvement in HI infants' ability to imitate.

A previous study by Ertmer and colleagues (1997) also investigated vowel imitations in CI and hearing aid users. 20 children, 10 hearing aid users and $10 \mathrm{CI}$ recipients, participated in the study (Ertmer et al., 1997). Children's ages ranged from four to eight years old. Children were asked to imitate live voice models of $10 \mathrm{CV}$ syllables, /b/ combined with six different vowels and four different diphthongs (Ertmer et al., 1997). Recordings were taken both pre- and post- device use/implantation.

Responses were recorded, broadly transcribed, and perceptually analyzed in nine areasvowels (high, low, front, and back), diphthong, and vowel features (height and place) (Ertmer et al., 1997). The study found that both groups produced low and back vowels with greater accuracy than high and front vowels pre-device use. Post-device use, CI users' accuracy of high vowels surpassed their accuracy of low vowels, while hearing aid users continued to produce low and back vowels with the most accuracy (Ertmer et al., 1997). CI users showed significant improvement on seven of nine measures of vowel imitation, while hearing aid users showed significant improvement in the production of diphthongs only. Overall, this study suggests that, while both CI and hearing aid users made improvements in vowel imitation after device use, the CI group showed greater overall improvement in imitative production of vowels (Ertmer et al., 1997), again indicating that use of CI's improves imitative abilities in infants with severe-profound hearing loss. 
Another study, by Ertmer and Goffman (2011), looked at vocal imitation of vowels and consonants in children with CIs compared to normal hearing children. This study was comprised of six children with CI's, ages three to five, and six normal hearing, age and gender matched children (Ertmer \& Goffman, 2011). Each child was asked to imitate four word lists from the First Words Speech Test. Responses were recorded and transcribed, and the percentage of initial consonants and vowels that were judged to be allophones of the target was determined (Ertmer \& Goffman, 2011, p. 5). The study found that the CI group had moderately lower accuracy scores for both consonants and vowels. Children in the NH group were near $100 \%$ accuracy for initial consonants on lists one through three and were $86 \%$ accurate for list four, while the CI group was $89 \%$ accurate for list one, $80 \%$ accurate for list two, 30\% accurate for list three, and $47 \%$ accurate for list four (Ertmer \& Goffman, 2011). The children in the normal hearing group got near ceiling scores for vowel accuracy on all lists, compared to an average of 79\%-84\% accuracy in the CI group (Ertmer \& Goffman, 2011). Overall, these findings show that both vowel and consonant imitation are problematic for CI users as compared to NH peers.

Although there is a body of research that examines how children with HL imitate, there is very little research examining the effect of infant hearing loss on mothers' vocal imitations; however, previous research has shown that hearing loss has an effect on maternal interactions with their infants (Bergeson, 2011; Cheskin, 1981; Fagan, Bergeson, \& Morris, 2014; Goss, 1970; Henggeler \& Cooper, 1983; Koester, Brooks, \& Karkowski, 1998; Tait et al., 2007). For example, mothers with HI infants have been shown to use shorter and less complex utterances, take fewer vocal turns with their 
infants, and overlap their infant's utterances at a greater rate compared to normal hearing dyads (Cheskin, 1981; Fagan et al., 2014; Koester et al., 1998; Tait et al., 2007).

It is well known from past studies with normal hearing children that both infant and maternal vocal matching play a key role in infant language development. Infant vocal matching allows for instant auditory feedback, providing reinforcement and allowing for immediate, direct comparison with the previous utterance (Papousek \& Papousek, 1989). Infant vocal imitation of mothers' vocalizations allows infants to learn linguistic structures, such as the specific inventory of phonetic units, words, and prosodic features that are used in a particular language (Karousou \& López-Ornat, 2013; Kuhl \& Meltzoff, 1996). The number of infant imitations, especially imitations of novel words, has positively linked with larger lexicons later in life (Masur, 1995; Masur \& Eichorst, 2002; Masur \& Olson, 2008). Some studies have suggested that imitation plays an important role in vocal learning (Kuhl \& Meltzoff, 1996). Vocal imitation may also promote infants' social use of language, specifically turn taking (Kuhl \& Meltzoff, 1982).

Maternal vocal matching is important because mothers' vocal matches promote infant vocal matching, and maternal vocal matching has been positively linked to infant language development (Masur, Flynn, \& Eichorst, 2005; Masur \& Olson, 2008; Masur \& Rodemaker, 1999; Olson \& Masur, 2012; Pelaez et al., 2011). As stated previously, research shows that mothers typically imitate more than infants (Masur \& Rodemaker, 1999). However, infants have been shown to vocalize more following mother imitation, suggesting that maternal imitation reinforces and promotes infant vocalization and imitation (Masur \& Rodemaker, 1999; Pelaez et al., 2011). Maternal imitation may also contribute to infants' later lexical development. For example, mothers tend to use more 
exact or reduced imitations following non-familiar infant imitations, creating a favorable environment for learning new words; but mothers use more expansive imitation following familiar infant utterances, exposing infants to more complex syntactic structures and facilitating language growth (Olson \& Masur, 2012). The number of maternal imitations has also been positively correlated with infant linguistic development (Masur et al., 2005; Masur \& Olson, 2008; Pelaez et al., 2011).

The aim of this study was to examine spontaneous vocal matching in natural interactions between mothers and infants with severe-profound hearing loss who have received CIs compared to vocal matching in mothers and infants with normal hearing $(\mathrm{NH})$. This study examined the quantity of vocal matches during spontaneous play between mothers and their NH and $\mathrm{HI}$ infants at a segmental level. Previous research has shown that vocal imitation is problematic for HI infants (Chin et al., 2012; Dillon et al., 2004; Ertmer \& Goffman, 2011; Ertmer et al., 1997; Nakata et al., 2012; Peng et al., 2008; Sehgal et al., 1998), indicating that in spontaneous vocal imitation, HI infants will likely imitate less compared to normal hearing peers. Past research has shown that maternal behavior is affected by hearing loss (Bergeson, 2011; Cheskin, 1981; Fagan et al., 2014; Goss, 1970; Henggeler \& Cooper, 1983; Koester et al., 1998; Kondaurova \& Bergeson, 2011; Kondaurova, Bergeson, \& Dilley, 2012; Kondaurova, Bergeson, \& Kitamura, 2013; Kondaurova, Bergeson, \& Xu, 2013; Kondaurova, Bergeson, Xu, \& Kitamura, 2015; Tait et al., 2007). Therefore, maternal imitation of their HI infants may also be negatively affected and they may imitate less as compared to mothers in the $\mathrm{NH}$ group. Based on previous research with $\mathrm{NH}$ and $\mathrm{HI}$ infants that demonstrated development of linguistic abilities over time (Fagan et al., 2014; Geers, Moog, 
Biedenstein, Brenner, \& Hayes, 2009; Houston, Stewart, Moberly, Hollich, \& Miyamoto, 2012; Krishon-Rabin, Taitelbaum-Swead, Ezrati-Vinacour, \& Hildesheimer, 2005; Miyamoto, Hay-McCutcheon, Kirk, Houston, \& Bergeson-Dana, 2008; Miyamoto, Svirsky, \& Robbins, 1997; Moeller et al., 2010; Papousek \& Papousek, 1989; Pisoni et al., 2008) it is predicted that in both groups matching will increase over the period of three testing sessions. 


\section{CHAPTER 2}

\section{METHODS}

\section{$\underline{\text { Participants }}$}

Normal-hearing mothers and their infants with profound sensorineural hearing loss who received CIs (HI group, $\mathrm{N}=9$ ) were recruited from the clinical population at the Indiana University School of Medicine, Department of Otolaryngology - Head and Neck Surgery. All mothers were reimbursed $\$ 10$ per visit. The HI group of participants was invited for three visits at three, six, and 12 months after CI stimulation. Table 1 shows the number of mother-infant dyads, the mean age and gender of hearing-impaired infants who completed testing at each session. All infants in this group were enrolled in education programs using oral communication. Table 2 provides available information on communication method, deafness etiology and the type of CI device for each infant in the hearing-impaired group.

Normal-hearing mothers of normal-hearing age-matched infants ( $\mathrm{NH}$ group, $\mathrm{N}=9$ ) were recruited from the local community and were reimbursed $\$ 10$ per visit. They were invited for three sessions: the first session coincided (in infants' age) with the first visit of hearing-impaired infants, the second and third sessions were at approximately three and nine months after the first visit, corresponding to the six and 12 month post-CI sessions of the HI group. These infants were the same chronological age as hearing-impaired infants at the time of each visit. 


\section{$\underline{\text { Procedure }}$}

Recordings

Mothers of both normal-hearing and hearing-impaired infants were digitally recorded in a single recording session speaking to their infants in a double-walled, copper-shielded sound booth (Industrial Acoustics Company). Mothers were asked to sit with their child on a blanket or a chair and to speak to their child as they normally would do at home while playing with quiet toys (ball, cat, dog, and fish). Each session lasted approximately three to five minutes. Mothers' speech was recorded in one of two ways: (a) a hypercardioid microphone (Audio-Technica ES933/H) powered by a phantom power source and linked to an amplifier (DSC 240) and digital audio tape recorder (Sony DTC-690) or (b) an SLX Wireless Microphone System (Shure). The latter system included an SLX1 Bodypack transmitter with a built-in microphone and a wireless receiver SLX4 which was connected to a Canon 3CCD Digital Video Camcorder GL2, NTSC. The speech samples were recorded directly onto a Mac computer (Apple, Inc. OSX Version 10.4.10) via Hack TV (Version 1.11) software.

\section{Coding of Vocalizations}

Using PRAAT 5.0.21 editor (Boersma \& Weenink, 2005), five total text tiers were created along the spectrogram and waveform. On the first text tier, based on visual and audio guidance, each recording was manually segmented into two types of events: an infant vocalization and an adjacent (preceding or following) mother vocalization. Either maternal of infant vocalization was defined as the production of a vocal sound by a conversation partner that was either continuous or included unvoiced segments of less 
than $3000 \mathrm{~ms}$ (Gratier et al., 2015). If the silent pause following an audible vocal sound produced by mother or infant was greater than $3000 \mathrm{~ms}$, two successive (mother or infant), vocalizations were identified. If the silent pause following or preceding an audible vocal sound produced by infant was greater than $3000 \mathrm{~ms}$, then the infant vocalization was defined as neither preceded nor followed by a maternal vocalization. Successive maternal vocalizations, simultaneous speech defined as any overlapping vocalizations of one conversation partner over another and vegetative sounds produced by either infant or mother were not coded.

On the second tier, mother and infant utterances that were adjacent to each other and separated by a pause less than $3000 \mathrm{~ms}$ were phonetically transcribed using the broad International Phonetic Alphabet.

The total number of sounds in each infant and mother utterance was recorded below the corresponding utterance on the third tier. On tier four, the number of sounds identical to mothers' sounds in an infant utterance following the mother's utterance [mother-infant (MI) turn] was recorded. On tier five, the number of sounds identical to infant's sounds in a mother utterance following an infant utterance [infant-mother (IM) turn] was recorded.

\section{Matching Score Calculation}

The matching score for an infant was calculated as a proportion, with the number of identical sounds in the infant and mother utterances divided by the number of sounds that the infant produced (Goldstein \& Schwade, 2008). For example, if a mother said "a fish" / $\mathrm{fr} \mathrm{f} /$, and the following infant utterance was /fide/, an infant utterance of /fide/ would receive a matching score of 50\% (two of the four phonemes matched). Any 
utterance that received a matching score greater than zero was considered at least a partial match. This method takes into account infants' partial matches of mothers' utterances (Goldstein \& Schwade, 2008). Repetitions of a matching sound did not change the matching score (Goldstein \& Schwade, 2008). The same procedure was used to calculate the matching score for the mother.

\section{Statistical Analysis}

Data reported as mean \pm one standard error $(\mathrm{M} \pm \mathrm{SE})$.

Analysis of Infant and Mother Vocalizations

To examine whether the infant hearing loss affected the (a) the number of infant and mother utterances and (b) the number of MI and IM turns a mixed-effects regression model (MRM) (Hedeker \& Gibbons, 2006; Vonesh \& Chinchilli, 1997) was run separately for infant and mother utterances. This model employs a general form of regression analysis with both fixed and random effects using the method of restricted maximum likelihood to estimate parameters (Kleinbaum, Kupper, Muller, \& Nizam, 1998; Vonesh \& Chinchilli, 1997). MRMs are especially useful in longitudinal research as they allow for missing data and for data that includes counts. Infant and mother utterances were analyzed separately because of two reasons. First, the number of infant and mother utterances was highly correlated $(r=.93)$ due to turn-taking and, second, it was difficult to interpret three-way interactions.

The model dimensions were as follows: (a) Fixed Effects: Group (HI, NH), Session (First, Second, Third) and Group x Session interaction, (b) Repeated Effects: Intercept. The MRM model calculated estimates of (a) the number of infant and mother utterances, and (b) the number of MI and IM turns. 
In addition, to examine the effect of Dyad (Infant, Mother), a mixed liner regression on the difference between (a) the number of infant and mother utterances and (b) the number of MI and IM turns was carried out adjusted for Group ( $H I, N H)$, Session (First, Second, Third) and Group x Session interaction.

To examine whether the infant hearing loss affected the (c) the length of utterances in sounds, a mixed liner regression was run. The model dimensions were the same as in the MRM model.

The degree of freedom in mixed linear regression models for (a) the number of infant and mother utterances, (b) the number of MI and IM turn and (c) the length of utterances in phonemes was calculated by Kenward-Roger Degrees of Freedom Approximation.

Analysis of Infant and Mother Vocalizations with a Matching Score $>0$ To examine whether there was an effect of infant hearing loss on the in the proportion of utterances with a matching score $>0$ produced by either Infant or Mother, we used a mixed liner regression model. The model dimensions were the same as in the MRM model.

To examine the effect of Dyad (Infant, Mother), a mixed liner regression on the difference between the proportion of infant and mother utterances with a matching score $>0$ was carried out adjusted for Group (HI, NH), Session (First, Second, Third) and Group $\mathrm{x}$ Session interaction. Figure 2 shows the distribution of the proportion of utterances with a matching score $>0$ out of all possible MI and IM turns in $\mathrm{HI}$ and $\mathrm{NH}$ groups. 


\section{CHAPTER 3}

\section{RESULTS \\ $\underline{\text { Infant and Mother Vocalizations }}$}

In total, we analyzed 1,282 infant and 1,677 mother utterances and $964 \mathrm{MI}$ and 980 IM turns. Table 3 presents mean number of infant and mother utterances, mean number of MI and IM turns and mean length utterances in sounds for both mother and infant vocalizations in $\mathrm{HI}$ and $\mathrm{NH}$ groups.

\section{The Number of Infant and Mother Utterances}

The results demonstrated a significant effect of Group [Infant: $\chi^{2}(1)=10.5, p=$ .001 ; Mother: $\left.\chi^{2}(1)=15.3, p<0.001\right]$, suggesting that there were fewer infant and mother utterances in HI (Infant: $M=14.7, S E=2.4$; Mother: $M=17.9, S E=2.7$ ) as compared to NH (Infant: $M=32.7, S E=3.3$; Mother: $M=44.1, S E=3.5$ ) group. For Infant and Mother utterances, there was also a significant effect of Session [Infant: $\chi^{2}(2)$ $=59, p<.001$; Mother: $\left.\chi^{2}(2)=8, p<.001\right]$. These results suggest that there was an increase in the number of infant and mother utterances over time (see Table 3). Following Wald $\mathrm{z}$ tests demonstrated a significant/marginally significant difference in the number of mother utterances over time Sessions 3 vs. 1 ( $p<0.001)$, Sessions 3 vs. $2(p=0.09)$, Sessions 1 vs. $2(p=0.02)$. These results suggest a gradual increase in the number of utterances produced by mothers of $\mathrm{HI}$ and NH infants (see Table 3). For infant productions, there was also a significant Group x Session interaction $\left[\chi^{2}(2)=10.8, p<\right.$ 
0.001] suggesting that there was a less steep increase in the number of utterances in the HI as compared to NH group (see Table 3).

There was also an effect of Dyad (Infant, Mother) as demonstrated by a mixed liner regression model. The intercept was significant $[t(26)=8.72, p<0.001]$ suggesting that, overall, mothers produced more utterances as compared to infants.

\section{The Number of MI and IM Turns}

The results demonstrated a significant effect of Group [MI: $\chi^{2}(1)=16.1, p<$ 0.001; IM: $\left.\chi^{2}(1)=15.7, p<0.001\right]$, suggesting that there were fewer MI and IM turns in HI [MI: $M=10.1, S E=1.6 ; \mathrm{IM}: M=10.4, S E=1.7]$ as compared to NH $[\mathrm{MI}: M=25.8$, $S E=2.3$; IM: $M=26.8, S E=2.4]$ group. There was also a significant effect of Session $\left[\mathrm{MI}: \chi^{2}(2)=62, p<0.001\right.$;M: $\left.\chi^{2}(2)=53.5, p<0.001\right]$. These results suggest that there was an increase in the number of MI and IM turns over time (see Table 3). Following Wald $\mathrm{z}$ tests demonstrated a significant increase in the number of MI (Sessions 3 vs. 1, $p$ $<0.001$, Sessions 1 vs. $2, p=0.05)$ and IM (Sessions 3 vs. $1, p<0.001)$ turns over time. No effect of Dyad (Infant, Mother) was identified.

\section{The Length of Utterances in Number of Sounds}

The mixed liner regression model demonstrated that for infants only there was a significant effect of Session $\left[\chi^{2}(2)=18.8, p<0.001\right]$ suggesting that, overall, infant length of utterances increased over time. Following Wald $\mathrm{z}$ tests demonstrated a significant increase at Sessions 3 vs. $1, p<0.001$ and Session 2 vs. $1, p=0.04$.

There was also an effect of Dyad (Infant, Mother) as demonstrated by a mixed linear regression model. The intercept was significant $[t(26)=8.2, p<0.001]$ suggesting that, overall, mothers produced longer utterances as compared to infants. 
In summary, the results demonstrated the effect of infant hearing status on the number of utterances and MI and IM turns produced by both infant and her mother. There were fewer utterances and turns in $\mathrm{HI}$ as compared to $\mathrm{NH}$ group. The results also demonstrated an increase in the number of utterances and MI and IM turns in both HI and $\mathrm{NH}$ groups over time. Mother produced longer utterances as compared to infants. There was also an increase in the length of utterances produced by infants over time.

$$
\text { Infant and Mother Vocalizations with a Matching Score }>0
$$

Due to the significant difference between $\mathrm{HI}$ and $\mathrm{NH}$ groups in the number of utterances and MI and IM turns, the proportion of infant and mother vocalizations with a matching score $>0$ out of all possible MI and IM turns for each participant was calculated. Figure 1 and Table 5 show the mean proportion of infant and mother utterances with a matching score $>0$ out of all possible MI and IM turns in $\mathrm{HI}$ and $\mathrm{NH}$ groups over the period of three sessions.

For both infant and mother utterances, the results demonstrated a significant effect of Group [Infant: $\chi^{2}(1)=4.73, p=0.03$; Mother: $\chi^{2}(1)=10.9, p<0.001$ ], suggesting that the proportion of utterances with a matching score $>0$ was smaller in HI (MI: $M=$ $0.33, S E=0.05 ; \mathrm{IM}: M=0.32, S E=0.05)$ as compared to $\mathrm{NH}(\mathrm{MI}: M=0.5, S E=0.03$; IM: $M=0.57, S E=0.04$ ) group. There was also a significant effect of Session [Infant: $\chi^{2}$ $(2)=10.3, p=0.006$; Mother: $\left.\chi^{2}(2)=18.04, p<0.001\right]$ suggesting that there was in increase in the proportion of the number of utterances with a matching score $>0$ produced over time (see Figure 1 and Table 5). Following Wald $\mathrm{z}$ tests demonstrated a significant increase in the proportion of utterances with a matching score $>0$ produced by 
infants at Session 3 vs. $1(p<0.001)$ and by mothers at Session 3 vs. $1(p<0.001)$ (see Figure 1 and Table 5). No effect of Dyad (Infant, Mother) was identified.

Overall, the results demonstrated a smaller proportion of utterances with a matching score $>0$ produced either by infant or her mother out of all adjacent utterances in $\mathrm{HI}$ as compared to $\mathrm{NH}$ groups. The results also demonstrated in increase in the proportion of utterances with a matching score $>0$ produced between the first and the third sessions by both $\mathrm{HI}$ and $\mathrm{NH}$ groups. 


\section{CHAPTER 4}

\section{DISCUSSION}

The purpose of this study was to examine the effect on hearing loss on the quantity of maternal and infant vocal matching along a segmental dimension in a naturalistic setting compared to a normal hearing, aged-matched control group. This study resulted in two major findings. First, it demonstrated that dyads with infants with hearing loss produced fewer number of utterances and vocal turns when compared to dyads in the NH group. An increase in number of utterances and turn-taking in both the normal hearing and hearing-impaired groups over time was noted. These results suggest a positive impact of intervention for hearing loss on language development for infants who received CIs (Geers et al., 2009). Second, this study found that both mothers and their infants with hearing loss produced a smaller proportion of utterances with matched sounds as compared to the NH group, demonstrating a negative effect of hearing loss on imitative abilities of both mothers and their infants.

The first finding of this study was the negative effect of infant hearing status on the total number of infant and mother utterances, as well as the number of MI and IM vocal turns. The results demonstrated that infants with hearing loss had fewer utterances compared to their normal hearing peers. Overall, these findings agree with and extend the body of previous literature suggesting infants with hearing loss produce fewer vocalizations as compared to infants with normal hearing (Eilers \& Oller, 1994; Fagan, 
2014; Geers et al., 2009; Krishon-Rabin et al., 2005; Nicholas \& Geers, 2007; Oller, Eilers, Bull, \& Carney, 1985; Schauwers, Gillis, \& Govaerts, 2005).

The results of the current study also suggest that there was an increase in the number of infant productions over time, thus, extending results of previous studies on $\mathrm{NH}$ and HI infants demonstrating infant language development over time (Fagan, 2014; Geers et al., 2009; Houston et al., 2012; Krishon-Rabin et al., 2005; Miyamoto et al., 2008; Miyamoto et al., 1997; Moeller et al., 2010; Pisoni et al., 2008).

The current study found that mothers in the HI dyads produced fewer utterances than mothers in $\mathrm{NH}$ dyads, indicating that infant hearing status has an effect on maternal vocal behavior. This agrees with previous literature that shows maternal speech to HI infants is affected by infant hearing loss (Chen, 1996; Cheskin, 1981; Cross, JohnsonMorris, \& Nienhuys, 1980; Kondaurova \& Bergeson, 2011; Kondaurova et al., 2012; Kondaurova, Bergeson, \& Kitamura, 2013; Kondaurova, Bergeson, \& Xu, 2013; Kondaurova et al., 2015; Kondaurova, Blank, Zheng, Abu Zhaya, \& Seidl, 2016; Nienhuys, Cross, \& Horsborough, 1984; Wieland, Burnham, Kondaurova, Bergeson, \& Dilley, 2015). Previous research has demonstrated that mothers use shorter utterances, exaggerated pitch characteristics, and a slower speaking rate when interacting with their HI infants (Kondaurova, Bergeson, \& Xu, 2013). Past research has also shown that mothers adjust prosodic features of speech according to infant hearing experience rather than the infant's chronological age when addressing their HI infants (Kondaurova \& Bergeson, 2011; Kondaurova, Bergeson, \& Kitamura, 2013). Research has also shown that mothers' vowel duration and pitch change in speech to HI infants were different compared to their normal hearing peers (Kondaurova \& Bergeson, 2011). Other studies 
demonstrated that mothers use shorter and less complex utterances, and are more likely to use restricted or limited vocabulary compared to mothers with NH peers (Cheskin, 1981; Fagan et al., 2014; Koester et al., 1998). The current study adds to this body of research by suggesting that $\mathrm{NH}$ mothers with $\mathrm{HI}$ infants tend to produce fewer utterances during natural interactions compared to NH mothers with $\mathrm{NH}$ infants.

This study's results also showed that mothers in both the $\mathrm{HI}$ and the NH groups increased their numbers of utterances over time, which is consistent with previous literature that shows mothers of hearing-impaired infants change their speech patterns over time (Bergeson, 2011; Kondaurova \& Bergeson, 2011; Kondaurova, Bergeson, \& $\mathrm{Xu}, 2013$; Kondaurova et al., 2015), as well as with research that demonstrates that mothers in general tend to expand and extend on infant utterances as their infants age (Cross et al., 1980).

The results of this study demonstrated fewer vocal turns, both in the MI and the IM direction, in the HI group as compared to $\mathrm{NH}$ group. This finding agrees with and extends previous research that demonstrated a break-down in reciprocity between a $\mathrm{NH}$ mother and her HI infant (Bergeson, 2011; Cheskin, 1981; Fagan et al., 2014; Goss, 1970; Henggeler \& Cooper, 1983; Koester et al., 1998; Quittner et al., 2013; Tait et al., 2007). A recent study suggests that normal hearing dyads produce a greater number of vocal turns compared to $\mathrm{HI}$ infants with $\mathrm{CIs}$ and their $\mathrm{NH}$ mothers, both before and after implantation (Tait et al., 2007). Another study showed that mothers' utterances overlapped with $\mathrm{HI}$ infant utterances at a greater rate when compared to normal hearing peers (Fagan et al., 2014). NH mothers with $\mathrm{HI}$ infants tended to use more prohibitions, or utterances containing "no", "not", or a contracted form that warn infants to stop a 
behavior, and directives, or imperative commands directing infant behavior, compared to the NH group (Fagan et al., 2014). Other studies also suggest that NH mothers' behavior with $\mathrm{HI}$ infants are more controlling and directive and are less responsive in vocal interactions as compared to NH dyads (Cheskin, 1981; Goss, 1970; Henggeler \& Cooper, 1983; Kondaurova et al., 2015).

The current study found that there was a smaller proportion of utterances with matching sounds in the $\mathrm{HI}$ infants as compared to their NH peers. This finding both supports and extends upon previous literature that has shown that imitation is problematic for children with hearing loss (Chin et al., 2012; Cleary et al., 2002; Dillon et al., 2004; Ertmer \& Goffman, 2011; Ertmer et al., 1997; Nakata et al., 2012; Peng et al., 2008; Sehgal et al., 1998). For example, children with hearing loss have been shown to have difficulty producing exact imitations of non-words, and their attempted repetitions tended to have fewer syllables as compared to the target (Cleary et al., 2002; Dillon et al., 2004). Children with hearing loss have also been shown to have trouble with imitation of both vowel and consonant sounds (Ertmer \& Goffman, 2011; Ertmer et al., 1997; Sehgal et al., 1998). Although this study did not examine what vowels and consonants $\mathrm{NH}$ and $\mathrm{HI}$ groups imitated, the findings of this study add to the previous studies (Chin et al., 2012; Cleary et al., 2002; Dillon et al., 2004; Ertmer \& Goffman, 2011; Ertmer et al., 1997; Nakata et al., 2012; Peng et al., 2008; Sehgal et al., 1998) by showing that the quantity of utterances with matched sounds is affected by infant hearing status.

The current study also demonstrated that there were fewer utterances that had sound matches in mother's speech to their $\mathrm{HI}$ infants. These results suggest that $\mathrm{NH}$ mothers' ability to match sounds is affected by infant hearing loss. Past studies focused 
predominantly on imitative abilities of infants and children with hearing loss (Chin et al., 2012; Cleary et al., 2002; Dillon et al., 2004; Ertmer \& Goffman, 2011; Ertmer et al., 1997; Nakata et al., 2012; Peng et al., 2008; Sehgal et al., 1998). The current study expands on past research (Chin et al., 2012; Cleary et al., 2002; Dillon et al., 2004; Ertmer \& Goffman, 2011; Ertmer et al., 1997; Nakata et al., 2012; Peng et al., 2008; Sehgal et al., 1998) by demonstrating that maternal ability to imitate is affected when they have an infant with hearing loss. Overall, these results agree and extend previous research suggesting that maternal speech is affected by infant hearing status (Bergeson, 2011; Fagan et al., 2014; Kondaurova \& Bergeson, 2011; Kondaurova, Bergeson, \& Kitamura, 2013; Tait et al., 2007).

The final finding of this study was that the proportion of both maternal and infant utterances with matches increased over time in both $\mathrm{HI}$ and $\mathrm{NH}$ groups. This finding has several implications. First, this finding agrees with previous literature that states that infants' language abilities improve following cochlear implantation (Fagan, 2014; Geers, 2004; Geers et al., 2009; Geers, Nicholas, \& Sedey, 2003; Miyamoto et al., 2008; Nicholas \& Geers, 2007; Niparko et al., 2010; Svirsky, Robbins, Kirk, Pisoni, \& Miyamoto, 2000; Svirsky, Teoh, \& Neuburger, 2004). Second, this finding also agrees with previous literature that has shown that imitative abilities of infants improve postdevice use (Ertmer et al., 1997; Sehgal et al., 1998). Finally, these results add to the existing body of literature on infants with $\mathrm{HI}$ by adding a maternal component; the current study's results show that mothers with HI infants increase their proportion of imitative utterances over time. This may show that use of an assistive device not only 
has positive implications for infant vocal imitation, but also has a positive effect on maternal imitative abilities.

Although the current study did not examine the quality of matched sounds, it is the first to demonstrate that $\mathrm{NH}$ mothers and their $\mathrm{HI}$ infants match each other's speech at the segmental level during spontaneous interactions. Previous research focused predominantly upon the ability of $\mathrm{HI}$ infants and children who received assistive devices to imitate in laboratory conditions following an example provided by an experimenter (Chin, Bergeson, \& Phan, 2012; Dillon, Cleary, Pisoni, \& Carter, 2004; Ertmer \& Goffman, 2011; Ertmer, Kirk, Sehgal, Riley, \& Osberger, 1997; Nakata, Trehub, \& Kanda, 2012; Peng, Tomblin, \& Turner, 2008; Sehgal, Kirk, Svirsky, Ertmer, \& Osberger, 1998). Thus, the results of the current study contribute to the body of previous literature by demonstrating a positive impact of a $\mathrm{CI}$ on the ability to imitate during natural interactions by both conversational partners.

This study has several limitations, and future research is need to understand what underlies imitative abilities in mothers and their HI children. First, the current study examined only the quantity of matches, or the proportion of utterances that had the same sounds in adjacent mother and infant vocalizations. Future research needs to explore the quality of matches, examining what sounds were imitated. Second, the current study did not analyze the prosodic dimension of mother and infant speech. Past research has documented that children with $\mathrm{HI}$ also have trouble with imitation at the prosodic level (Carter, Dillon, \& Pisoni, 2002; Chin et al., 2012; Dillon et al., 2004; Frank \& Bergman, 1987; Nakata et al., 2012; Peng et al., 2008; Wang, Trehub, Volkova, \& van Lieshout, 2013). Consequently, it is necessary to observe both segmental and prosodic dimensions 
while analyzing imitative abilities of $\mathrm{NH}$ mothers and their $\mathrm{HI}$ infants. Future research needs to include more dyads in each group to reduce large individual variability in matching observed in the current study. Future research should include dyads with NH mother and $\mathrm{NH}$ infants with equal hearing experience as the $\mathrm{HI}$ infants to understand the mechanisms and the development of imitation over time. 
Table 1. Number of dyads, mean age of infants at each session, and sex of infants, presented as mean $\pm \mathrm{SE}$

\begin{tabular}{lccc}
\hline \multicolumn{1}{c}{ Session } & \# of Dyads & Age & Sex \\
\hline HI Group & 9 & $19.0 \pm 1.4$ & M8, F1 \\
3 months post CI stim & 9 & $22.2 \pm 1.5$ & M8, F1 \\
6 months post CI stim & 9 & $28.5 \pm 1.5$ & M8, F1 \\
12 months post CI stim & 9 & & \\
$\quad$ NH Group & 9 & $22.2 \pm 1.5$ & M4, F5 \\
1 session & 9 & $28.5 \pm 1.5$ & M4, F5 \\
2 session & & & M4, F5 \\
3 session & & & \\
\hline
\end{tabular}


Table 2. Communication method, deafness etiology, and the type of CI device

\begin{tabular}{|c|c|c|c|}
\hline Participant & Device (L-left ear; R-right ear) & $\begin{array}{l}\text { Communication } \\
\text { method }\end{array}$ & Etiology \\
\hline 1 & Nucleus 24 contour, $R$ & $\mathrm{OC}, \mathrm{TC}$ & Unknown \\
\hline 2 & Med El C $40+$, R & $\mathrm{OC}$ & $\begin{array}{l}\text { Brachio-oto-renal } \\
\text { Syndrome }\end{array}$ \\
\hline 3 & $\begin{array}{l}\text { Nucleus freedom-contour advance, } \\
\mathrm{R}\end{array}$ & Unavailable & Unknown \\
\hline 4 & $\begin{array}{l}\text { Nucleus freedom-contour advance, } \\
\mathrm{R}\end{array}$ & Unavailable & Unknown \\
\hline 5 & Nucleus 24 contour, $\mathrm{R}$ & $\mathrm{OC}$ & $\begin{array}{l}\text { Connexin 26- } \\
\text { DFNB/35delG allele } \\
\text { variant/GJB2/DFNB1 }\end{array}$ \\
\hline 6 & $\begin{array}{l}\text { Nucleus freedom-contour advance, } \\
\mathrm{L}\end{array}$ & $\mathrm{OC}$ & Mild Mondini \\
\hline 7 & Nucleus 24 contour, L & $\mathrm{OC}$ & Unknown \\
\hline 8 & Nucleus 24 contour advance, $L$ & $\mathrm{OC}$ & Unknown \\
\hline 9 & HiRes $90 \mathrm{~K}, \mathrm{R}$ & $\mathrm{TC}$ & Unknown \\
\hline
\end{tabular}


Table 3. Mean number of utterances, mother-infant and infant-mother turns and mean length of utterances in phonemes in $\mathrm{HI}$ and $\mathrm{NH}$ groups, presented as mean $\pm \mathrm{SE}$

\begin{tabular}{ccccccc}
\hline & \multicolumn{2}{c}{ Number of utterances } & \multicolumn{2}{c}{ Number of turns } & \multicolumn{2}{c}{$\begin{array}{c}\text { Utterance length in } \\
\text { phonemes }\end{array}$} \\
& Infant & Mother & MI & IM & MI & IM \\
\hline $\begin{array}{c}\text { HI Group } \\
\text { 3 months } \\
\text { post CI stim }\end{array}$ & $13.8 \pm 4.0$ & $14.9 \pm 3.0$ & $7.6 \pm 1.7$ & $8.2 \pm 2.0$ & $1.9 \pm 0.2$ & $7.3 \pm 0.6$ \\
$\begin{array}{c}\text { 6 months } \\
\text { post CI stim }\end{array}$ & $14.1 \pm 4.6$ & $15.9 \pm 5.0$ & $9.1 \pm 3.1$ & $9.3 \pm 3.1$ & $2.9 \pm 0.7$ & $7.3 \pm 0.8$ \\
$\begin{array}{c}\text { 12 months } \\
\text { post CI stim }\end{array}$ & $16.3 \pm 4.4$ & $24.0 \pm 5.5$ & $13.7 \pm 3.3$ & $13.7 \pm 3.3$ & $3.6 \pm 0.5$ & $8.1 \pm 0.6$ \\
$\begin{array}{c}\text { NH Group } \\
\text { Session 1 }\end{array}$ & $24.4 \pm 4.2$ & $33.3 \pm 5.1$ & $19.3 \pm 3.1$ & $20.9 \pm 3.3$ & $2.5 \pm 0.3$ & $7.9 \pm 0.7$ \\
Session 2 & $28.1 \pm 3.8$ & $41.6 \pm 4.3$ & $23.6 \pm 2.7$ & $21.4 \pm 4.0$ & $3.0 \pm 0.2$ & $8.6 \pm 0.6$ \\
& & & & & & \\
Session 3 & $45.6 \pm 6.7$ & $57.6 \pm 6.4$ & $33.9 \pm 4.3$ & $35.2 \pm 4.8$ & $4.1 \pm 0.4$ & $9.5 \pm 0.7$ \\
\hline
\end{tabular}


Table 4. Length of utterances in phonemes and as a proportion of a preceding utterance in mother-infant and infant-mother turns, presented as mean $\pm \mathrm{SE}$

\begin{tabular}{lcccc}
\hline & \multicolumn{2}{c}{$\begin{array}{c}\text { Length of utterance in } \\
\text { sounds }\end{array}$} & \multicolumn{2}{c}{$\begin{array}{c}\text { Length of utterance as a } \\
\text { proportion }\end{array}$} \\
& Infant & Mother & $\begin{array}{c}\text { Infant/ } \\
\text { (Infant+Mother) }\end{array}$ & $\begin{array}{c}\text { Mother/ } \\
\text { (Infant+Mother) }\end{array}$ \\
\hline $\begin{array}{l}\text { HI Group } \\
\text { 3 months post CI stim }\end{array}$ & $1.9 \pm 0.2$ & $7.3 \pm 0.6$ & $0.2 \pm 0.0$ & $0.7 \pm 0.0$ \\
6 months post CI stim & $2.9 \pm 0.7$ & $7.3 \pm 0.8$ & $0.2 \pm 0.1$ & $0.7 \pm 0.0$ \\
12 months post CI stim & $3.6 \pm 0.5$ & $8.1 \pm 0.6$ & $0.3 \pm 0.0$ & $0.6 \pm 0.0$ \\
NH Group & & & & \\
Session 1 & $2.5 \pm 0.3$ & $7.9 \pm 0.7$ & $0.3 \pm 0.0$ & $0.6 \pm 0.1$ \\
Session 2 & $3.0 \pm 0.2$ & $8.6 \pm 0.6$ & $0.3 \pm 0.0$ & $0.7 \pm 0.0$ \\
Session 3 & $4.1 \pm 0.4$ & $9.5 \pm 0.7$ & $0.3 \pm 0.0$ & $0.6 \pm 0.0$ \\
\hline
\end{tabular}


Table 5. Proportion of infant and mother utterances with a matching score $>0$ out of all mother-infant and infant-mother turns in $\mathrm{HI}$ and $\mathrm{NH}$ groups, presented as mean $\pm \mathrm{SE}$

\begin{tabular}{lcc}
\hline & \multicolumn{2}{c}{ Proportion of utterances with a matching score $>\mathbf{0}$} \\
& Infant (out of all MI turns) & Mother (out of all IM turns) \\
\hline HI Group & $0.2 \pm 0.1$ & $0.2 \pm 0.1$ \\
3 months post CI stim & $0.3 \pm 0.1$ & $0.4 \pm 0.1$ \\
6 months post CI stim & $0.5 \pm 0.1$ & $0.4 \pm 0.1$ \\
12 months post CI stim & & $0.5 \pm 0.1$ \\
NH Group & $0.4 \pm 0.1$ & $0.6 \pm 0.0$ \\
Session 1 & $0.6 \pm 0.1$ & $0.6 \pm 0.0$ \\
Session 2 & $0.5 \pm 0.0$ & \\
Session 3 & &
\end{tabular}




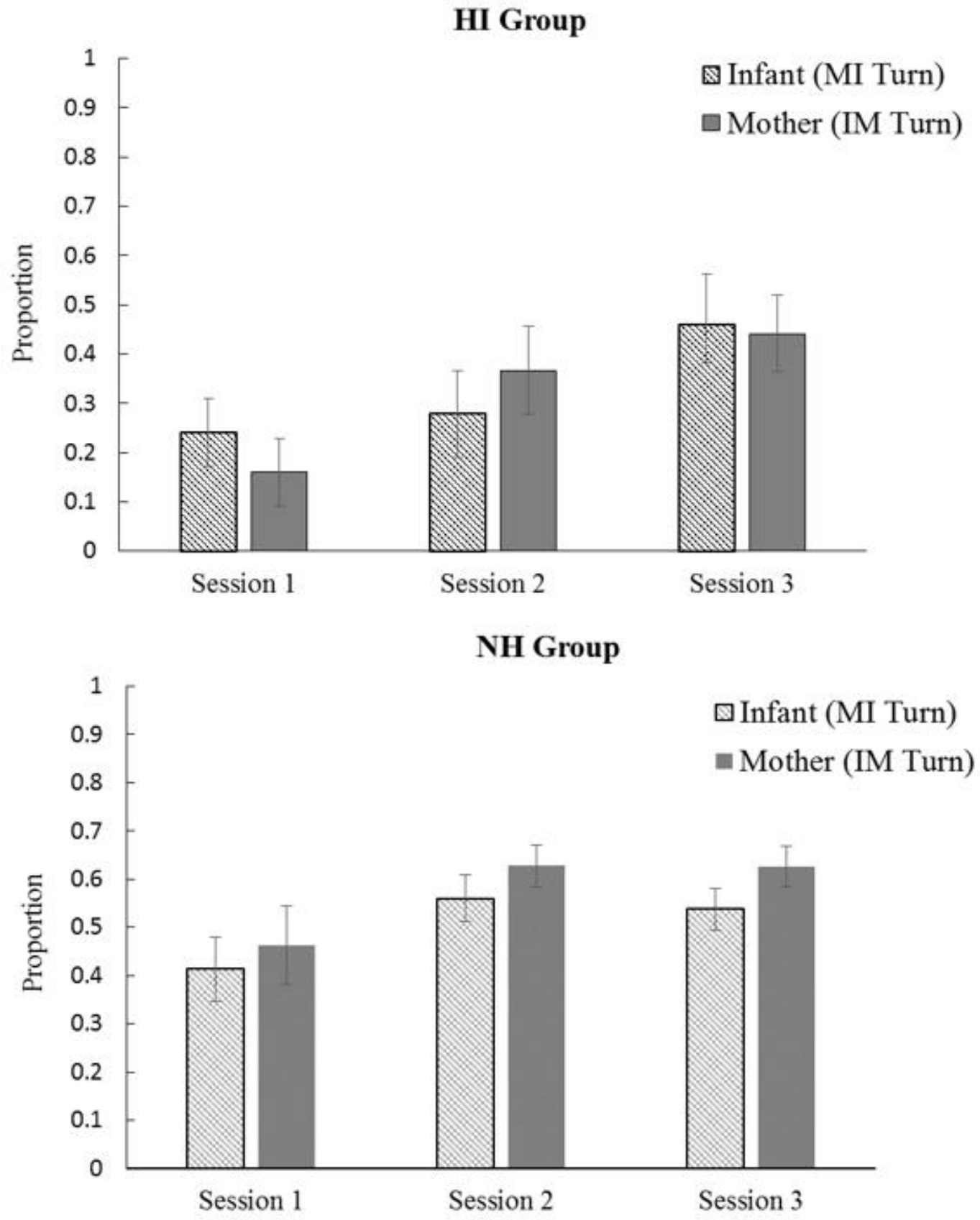

Figure 1. The mean proportion of utterances with a matching score $>0$ out of all possible MI and IM turns in HI and NH groups over the period of three sessions. 

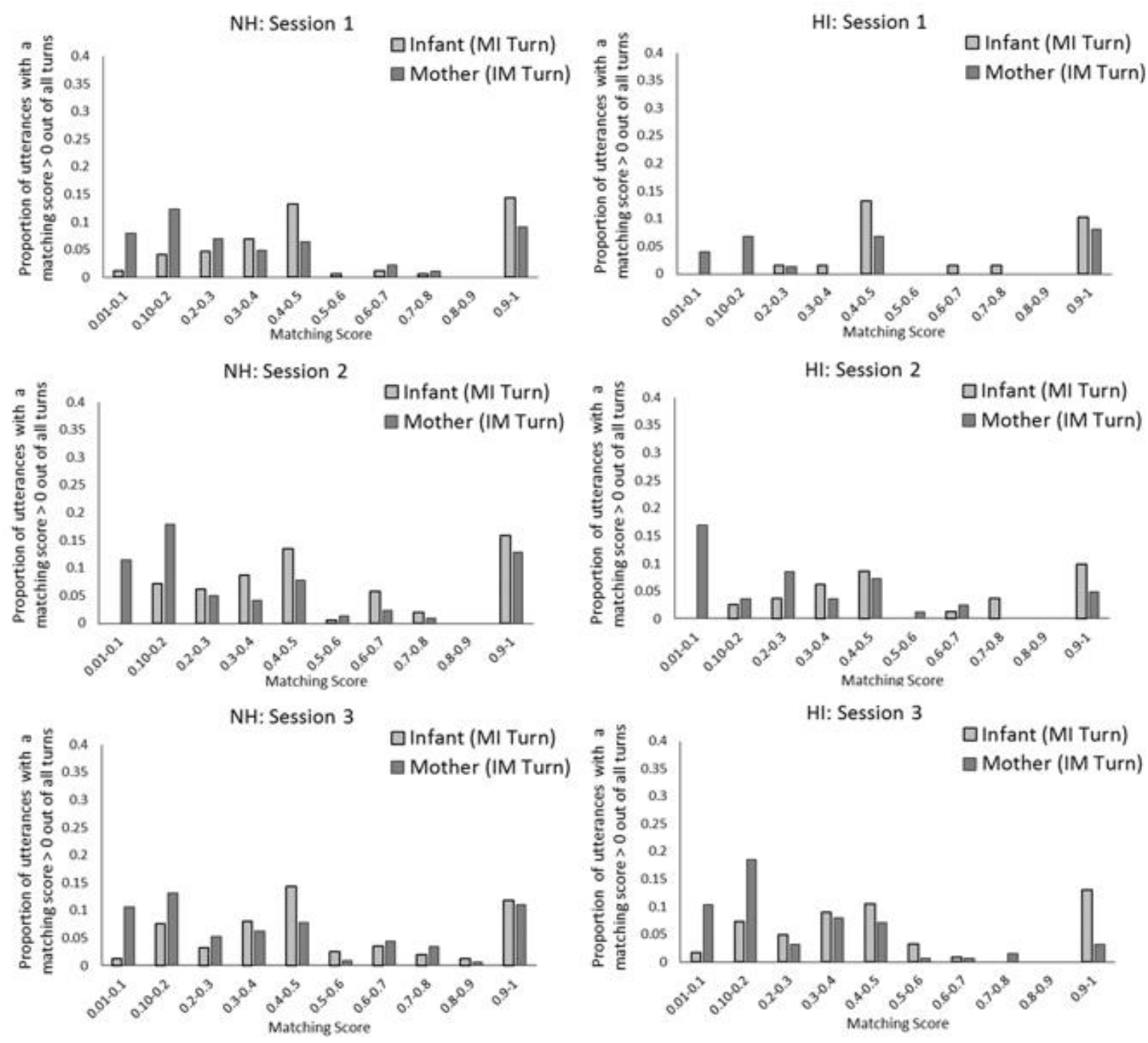

Figure 2. The distribution of the proportion of utterances with a matching score $>0$ out of all possible MI and IM turns in $\mathrm{HI}$ and $\mathrm{NH}$ groups at each testing session. 


\section{REFERENCES}

Beebe, B., Jaffe, J., Markese, S., Buck, K., Chen, H., Cohen, P., Bahrick, L., Andrews, H., \& Feldstein, S. (2010). The Origins of 12-Month Attachment: A Microanalysis of 4-Month Mother-Infant Interaction. Attachment \& Human Development, 12(1-2), 3-141.

Bergeson, T. R. (2011). Maternal speech to hearing-impaired infants in the first year of hearing aid or cochlear implant use: a preliminary report. Cochlear Implants International, 12, S101-S104.

Bloom, L., Hood, L., \& Lightbown, P. (1974). Imitation in language development: if, when, and why. Cognitive Psychology, 6(3), 380-420.

Boersma, P., \& Weenink, D. (2005). PRAAT: doing phonetics by computer (Version 5.0.21) [Computer program]. Retrieved 01/01/10, 2010, from http://www.praat.org/

Carter, A. K., Dillon, C. M., \& Pisoni, D. B. (2002). Imitation of nonwords by hearing impaired children with cochlear implants: suprasegmental analyses. Journal of Linguistics and Phonetics, 16(8), 619-638.

Chen, D. (1996). Parent-infant communication: early intervention for very young children with visual impairment or hearing loss. Infants \&Young Children, 9(2), $1-12$.

Cheskin, A. (1981). The verbal environment provided by hearing mothers for their young deaf children. Journal of Communication Disorders, 14, 485-496.

Chin, S. B., Bergeson, T. R., \& Phan, J. (2012). Speech intelligibility and prosody production in children with cohlear implants. Journal of Communicative Disorders, 45, 355-366.

Cleary, M., Dillon, C., \& Pisoni, D. B. (2002). Imitation of nonwords by deaf children after cochlear implantation: preliminary findings. Annals of otology, Rhinology, and Laryngology, 111.

Cross, T. G., Johnson-Morris, J., \& Nienhuys, T. (1980). Linguistic feedback and maternal speech comparisons of mothers addressing hearing and hearing-impaired children. First Language, 1, 163-189 
Cross, T. G., Nienhuys, T. G., \& Kirkman, M. (1985). Parent-child interaction with receptively disabled children: Some determinants of maternal speech style. In K. E. Nelson (Ed.), Child Language (Vol. 5). Hillsdale, NJ: Lawrence Earlbaum Associates, Inc.

Dillon, C., Cleary, M., Pisoni, D. B., \& Carter, A. (2004). Imitation of nonwords by hearing-impaired children with cochlear implants: segmental analyses. Clinical Linguistics and Phonetics, 18(1), 39-55.

Eilers, R. E., \& Oller, D. K. (1994). Infant vocalizations and the early diagnosis of severe hearing impairment. The Journal of Pediatrics, 124(2), 199-203.

Ertmer, D. J., \& Goffman, L. (2011). Speech production accuracy and variability in young cochlear implant recipients: comparisons with typically developing peers. Journal of Speech, Language and Hearing Research, 54, 177-189.

Ertmer, D. J., Kirk, K. I., Sehgal, S. T., Riley, A. I., \& Osberger, M. J. (1997). A comparison of vowel production by children with multichannel cochlear implants or tactile aids: perceptual evidence. Ear \& Hearing, 18(4), 307-315.

Fagan, M. K. (2014). Frequency of vocalizations before and after cochlear implantation: Dynamic effect of auditory feedback on infant behavior. Journal of Experimental Child Psychology, 126, 328-338.

Fagan, M. K., Bergeson, T. R., \& Morris, K. J. (2014). Synchrony, complexity and directiveness in mothers' interactions with infants pre- and post-cochlear implantation. Infant Behavior \& Development, 37(3), 249-257.

Frank, Y., \& Bergman, M. (1987). Stress and intonation in the speech of hearingimpaired hebrew-speaking children. Language and Speech, 30(4).

Gazdag, G., \& Warren, S. F. (2000). Effects of adult contingent imitation on development of young children's vocal imitation. Journal of Early Intervention, 23(1), 24-35.

Geers, A. E. (2004). Speech, language, and reading skills after early cochlear implantation. Archives of Otolaryngology-Head \& Neck Surgery, 130(5), 634638.

Geers, A. E., Moog, J., Biedenstein, J., Brenner, C., \& Hayes, H. (2009). Spoken language scores of children using cochlear implants compared to hearing agemates at school entry. Journal of Deaf Studies and Deaf Education, 14(3), 371385 .

Geers, A. E., Nicholas, J. G., \& Sedey, A. L. (2003). Language skills of children with early cochlear implantation. Ear and Hearing, 24(1), 46S-58S. 
Goldstein, M. H., King, A. P., \& West, M. J. (2003). Social interaction shapes babbling: Testing parallels between birdsong and speech. Proceedings of the National Academy of Sciences, USA, 100, 8030-8035.

Goldstein, M. H., \& Schwade, J. A. (2008). Social feedback to infants' babbling facilitates rapid phonological learning. Psychological Science, 19, 515-523.

Goss, R. N. (1970). Language used by mothers of deaf children and mothers of hearing children. American Annals of the Deaf, 115, 93-96.

Gratier, M., Devouche, E., Guellai, B., 1, Rubia, Infanti, R., Yilmaz, E., \& ParlatoOliveira, E. (2015). Early development of tunr-taking in vocal interaction between mothers and infants. Frontiers in psychology, 6, 1-10.

Gros-Louis, J., West, M. J., Goldstein, M. H., \& King, A. P. (2006). Mothers provide different feedback to infants' prelinguistic sounds. International Journal of Behavioral Development, 30(6), 509-516.

Hedeker, D., \& Gibbons, R. D. (2006). Longitudinal data analysis (Wiley series in probability and statistics). Hoboken, New Jersey: John Wiley and Sons, Inc.

Heimann, M. (1998). Imitation in neonates, in older infants, and in children with autism: Feedback to theory. In S. Braten (Ed.), Intersubjective Communication and Emotion in Early Ontogeny (pp. 89-104). Cambridge: Cambridge University Press.

Henggeler, S. W., \& Cooper, P. F. (1983). Deaf child - hearing mother interaction: extensiveness and reciprocity. Journal of Pediatric Psychology, 8(1), 83-95.

Houston, D. M., Stewart, J., Moberly, A., Hollich, G., \& Miyamoto, R. T. (2012). Word learning in deaf children with cochlear implants: effects of early auditory experience. Developmental Science, 15(3), 448-461.

Hudson, S., Levickis, P., Down, K., Nicholls, R., \& Wake, M. (2015). Maternal responsiveness predicts child language at ages 3 and 4 in a community-based sample of slow-to-talk toddlers. International Journal of Language \& Communication Disorders, 50(1), 136-142.

Iyer, S., \& Oller, D. K. (2008). Prelinguistic Vocal Development in Infants with Typical Hearing and Infants with Severe-to-Profound Hearing Loss. The Volta Review, 108(2), 115-138. 
Karousou, A., \& López-Ornat, S. (2013). Prespeech Vocalizations and the Emergence of Speech: A Study of 1005 Spanish Children. Spanish Journal of Psychology, 16(e32), 1-21.

Kleinbaum, D. G., Kupper, L. L., Muller, K. E., \& Nizam, A. (1998). Applied regression analysis and other multivariate methods. Pacific Grove, CA: Duxbury Press.

Koester, L. S., Brooks, L. R., \& Karkowski, A. M. (1998). A comparison of vocal patterns of deaf and hearing mother-infant dyads during face-to-face interactions. Journal of Deaf Studies and Deaf Education, 3, 290-301.

Kokkinaki, T., \& Kugiumutzakis, G. (2000). Basic aspects of vocal imitation in infantparent interaction during the first 6 months. Journal of Reproductive and Infant Psychology, 18(3), 173-187.

Kondaurova, M. V., \& Bergeson, T. R. (2011). The effects of age and infant hearing status on maternal use of prosodic cues for clasue boundaries in speech. Journal of Speech, Language and Hearing Research, 54, 740-754.

Kondaurova, M. V., Bergeson, T. R., \& Dilley, L. C. (2012). Effects of deafness on acoustic characteristics of american english tense/lax vowels in maternal speech to infants. Journal of the Acoustical Society of America, 132(2), 1039-1049.

Kondaurova, M. V., Bergeson, T. R., \& Kitamura, C. (2013). Communicative intent and affect in mothers' speech to hearing-impaired infants with cochlear implants. Journal of the Acoustical Society of America, 134(5), 4133.

Kondaurova, M. V., Bergeson, T. R., \& Xu, H. (2013). Age-related changes in prosodic features of maternal speech to prelingually deaf infants with cochlear implants. Infancy, 1-24.

Kondaurova, M. V., Bergeson, T. R., Xu, H., \& Kitamura, C. (2015). Affective properties of mothers' speech to hearing-impaired infants with cochlear implants. Journal of Speech, Language and Hearing Research., 58(3), 590-600.

Kondaurova, M. V., Blank, A. L., Zheng, Q., Abu Zhaya, R., \& Seidl, A. (2016). Temporal organization of vocal turn-taking between mothers and hearingimpaired infants with cochlear implants The 23rd Annual Appalachian Spring Conference: Current Trends In Cochlear Implants, June 9-10, 2016, Stanton Gerber Hall, ETSU. James H. Quillen VA Medical Center. Mountain Home VA Medical Center Campus, Johnson City, TN.

Krishon-Rabin, L., Taitelbaum-Swead, R., Ezrati-Vinacour, R., \& Hildesheimer, M. (2005). Prelexical Vocalization in normal hearing and hearing-impaired infants 
before and after cochlear implantation and its relation to early auditory skills. Ear and Hearing, 26(4), 17S-29S.

Kucjaz, S. A. (1983). Crib speech and language play. New York: Springer-Verlag.

Kugiumutzakis, G. (1993). Intersubjective vocal imitation in early mother-infant interaction. In J. Nadel \& L. Camaioni (Eds.), New perspectives in early communicative development (pp. 23-47). London, England: Routledge.

Kugiumutzakis, G. (1998). Neonatal imitation in the intersubjective companion space. In S. Braten (Ed.), Intersubjective Communication and Emotion in Early Ontogeny (pp. 63-88). Cambridge: Cambridge University Press.

Kugiumutzakis, G. (1999). Genesis and development of early infant mimesis to facial and vocal models. In J. Nadel \& G. Butterworth (Eds.), Imitation in infancy (pp. 127185). Cambridge: Cambridge University Press.

Kuhl, P. K., \& Meltzoff, A. N. (1982). The bimodal perception of speech in infancy. Science, 218, 1138-1141.

Kuhl, P. K., \& Meltzoff, A. N. (1996). Infant vocalizations in response to speech: vocal imitation and developmental change. The Journal of the Acoustical Society of America, 100(4), 2425-2438.

Masur, E. F. (1993). Transitions in representational ability: Infants' verbal, vocal, and action imitation during the second year. Merrill-Palmer Quarterly, 39, 437-456.

Masur, E. F. (1995). Infants' early verbal imitation and their later lexical development. Merrill-Palmer Quarterly, 41(3), 286-306.

Masur, E. F., \& Eichorst, D. L. (2002). Infants' Spontaneous Imitation of Novel Versus Familiar Words: Relations to Observational and Maternal Report Measures of Their Lexicons. Merrill-Palmer Quarterly, 48(4), 405-426.

Masur, E. F., Flynn, V., \& Eichorst, D. L. (2005). Maternal responsive and directive behaviors and utterances as predictors of chidren's lexical development. Journal of Child Language, 32, 63-91.

Masur, E. F., \& Olson, J. (2008). Mothers' and infants' responses to their partners' spontaneous action and vocal/verbal imitation. Infant Behavior \& Development, 31, 704-715.

Masur, E. F., \& Rodemaker, J. E. (1999). Mothers' and infants' spontaneous vocal, verbal, and action imitation during the second year. Merrill-Palmer Quarterly, 45(3). 
Mercado, E., Mantell, J. T., \& Pfordresher, P. Q. (2014). Imitating sounds: a cognitive approach to understanding vocal imitation. Comparative Cognition \& Behavior Reviews, 9.

Miyamoto, R. T., Hay-McCutcheon, M. J., Kirk, K. I., Houston, D. M., \& BergesonDana, T. (2008). Language skills of profoundly deaf children who received cochlear implants under 12-months of age: a preliminary study. Acta OtoLaryngologica, 128(4), 373.

Miyamoto, R. T., Svirsky, M. A., \& Robbins, A. M. (1997). Enhancement of expressive language in prelingually deaf children with cochlear implants. Acta Otolaryngology, 117, 154-157.

Moeller, M. P., McCleary, E., Putman, C., Tyler-Krings, A., Hoover, B., \& Stelmachowicz, P. (2010). Longitudinal development of phonology and morphology in children with late-identified mild-moderate sensorineural hearing loss. Ear and Hearing, 31(5), 625-635.

Nakata, T., Trehub, S. E., \& Kanda, Y. (2012). Effect of cochlear implants on children's perception and production of speech prosody. Journal of the Acoustical Society of America, 131(2), 1307-1314.

Nicholas, J. G., \& Geers, A. E. (2007). Will they catch up? the role of age at cochlear implantation in the spoken language development of children with severeprofound hearing loss. Journal of Speech, Language and Hearing Research, 50(4), 1048-1062.

Nienhuys, T. G., Cross, T. G., \& Horsborough, K. M. (1984). Child variables influencing maternal speech style: Deaf and hearing children. Journal of Communication Disorders, 17(3), 189-207.

Niparko, J. K., Tobey, E. A., Thal, D. J., Eisenberg, L. S., Wang, N.-Y., Quittner, A. L., \& Fink, N. E. (2010). Spoken language development in children following cochlear implantation. Journal of American Medical Association, 303 (15), 14981506.

Oller, D. K., Eilers, R. E., Bull, D. H., \& Carney, A. E. (1985). Prespeech vocalizations of a deaf infant: a comparison with normal metaphonological development. Journal of Speech, Language and Hearing Research, 28(1), 47-63.

Olson, J., \& Masur, E. F. (2012). Mothers respond differently to infants' familiar versus non-familiar verbal imitations. Journal of Child Language, 39(4), 731-752. 
Papousek, M. (1992). Early ontogeny of vocal communicatio in parent-infant interactions. In H. Papousek, U. Jurgen \& M. Papousek (Eds.), Nonverbal vocal communication: Comparative and developmental approaches (pp. 230-261). Cambridge, England: Cambridge University Press.

Papousek, M., \& Papousek, H. (1989). Forms and functions of vocal matching in interactions between mothers and their precanonical infants. First Language, 9, 137-158.

Pelaez, M., Virues-Ortega, J., \& Gerwirtz, J. L. (2011). Reinforcement of vocalizations through contingent vocal imitation. Journal of Applied Behavior Analysis, 44, 33 40 .

Peng, S.-C., Tomblin, J. B., \& Turner, C. W. (2008). Production and perception of speech intonation in pediatric cochlear implant recipients and individuals with normal hearing. Journal of Ear and Hearing, 29(3), 336-351.

Pisoni, D. B., Conway, C. M., Kronenberger, W. C., Horn, D. L., Karpicke, J., \& Henning, S. C. (2008). Efficacy and effectiveness of cochlear implants in deaf children. In M. Marschark \& P. C. Hauser (Eds.), Deaf cognition: foundations and outcomes (pp. 52-100). US: Oxford University Press.

Quittner, A. L., Cruz, I. S., Barker, D. H., Tobey, E., Eisenberg, L. S., \& Niparko, J. K. (2013). Effects of maternal sensitivity and cognitive and linguistic stimulation on cochlear implant users' language development over four years. The Journal of Pediatrics, 162(2), 343-348.

Schauwers, K., Gillis, S., \& Govaerts, P. (2005). Language acquisition in children with a cochlear implant. In P. Fletcher \& J. F. Miller (Eds.), Developmental theory and language disorders (Vol. 4, pp. 95-120). Philadelphia, PA: John Benjamins.

Sehgal, S. T., Kirk, K. I., Svirsky, M., Ertmer, D. J., \& Osberger, M. J. (1998). Imitative consonant feature production by children with multichannel sensory aids. Ear \& Hearing, 19(1), 72-84.

Snow, C. E. (1977). The development of conversation between mothers and babies. Journal of Child Language, 4, 1-22.

Snow, C. E. (1981). The uses of imitation. Journal of Child Language, 8, 205-212.

Svirsky, M. A., Robbins, A. M., Kirk, K. I., Pisoni, D. B., \& Miyamoto, R. T. (2000). Language development in profoundly deaf children with cochlear implants. Psychological Science, 11(2), 153-158. 
Svirsky, M. A., Teoh, S. W., \& Neuburger, H. (2004). Development of language and speech perception in congenitatlly, profoundly deaf children as a function of age at cochlear implantation. Audiology and Neurotology, 9(4), 224-233.

Tait, M., De Raeve, L., \& Nikolopoulos, T. P. (2007). Deaf children with cochlear implants before the age of 1 year: Comparis on of preverbal communication with normally hearing children. International Journal of Pediatric Otorhinolaryngology, 71, 1605-1611.

Vonesh, E. F., \& Chinchilli, V. M. (1997). Linear and non-linear models for the analysis of repeated measurements. New York, NY: Marcel Dekker, Inc.

Wang, D. J., Trehub, S. E., Volkova, A., \& van Lieshout, P. (2013). Child implant users' imitation of happy- and sad-sounding speech. Frontiers in psychology, 4.

Wieland, E. A., Burnham, E. B., Kondaurova, M., Bergeson, T. R., \& Dilley, L. C. (2015). Vowel space characteristics of speech directed to children with and without hearing loss. Journal of Speech, Language and Hearing Research., 58, 254-267. 


\section{APPENDIX: ABBREVIATIONS}

$\begin{array}{ll}\text { NH } & \text { Normal Hearing } \\ \text { HI } & \text { Hearing Impaired } \\ \text { CIs } & \text { Cochlear Implants } \\ \text { MI } & \text { Mother-Infant (vocal turn) } \\ \text { IM } & \text { Infant-Mother (vocal turn) } \\ \text { M } \pm \text { SE } & \text { Mean } \pm \text { Standard Error }\end{array}$




\section{CURRICULUM VITAE}

NAME: $\quad$ Lydia Margaret Doggett

ADDRESS: Department of Otolaryngology, Head and Neck Surgery and Communicative Disorders

627 S. Preston Street

University of Louisville

Louisville, KY 40242

EDUCATION

\& TRAINING: $\quad$ B.S. Communication Sciences and Disorders University of Kentucky

2011-15

M.S. Communicative Disorders

University of Louisville

2015-17

AWARDS:

PROFESSIONAL SOCIETIES:

PUBLICATIONS:

NATIONAL MEETING PRESENTATIONS:

REFERRED JOURNALS:

BOOKS AND SYMPOSIA:

INVITED PRESENTATIONS: 